\title{
Long-term survival of adult Arctic grayling (Thymallus arcticus) in the Kuparuk River, Alaska
}

\author{
Karen M. Buzby and Linda A. Deegan
}

\begin{abstract}
In many long-lived species such as Arctic grayling (Thymallus arcticus), population growth rate is most sensitive to changes in adult survival probabilities. Understanding the factors that regulate adult survival in this species should provide insight into the population dynamics of this and other long-lived Arctic species. Using the program MARK, we analyzed 17 years of mark-recapture data to estimate survival rates for Arctic grayling in the Kuparuk River, Alaska, from 1985 to 2000 . Mean annual survival rates overall ranged from 0.39 to 1.0 and averaged $0.71 \pm$ 0.05 for resident and $0.75 \pm 0.05$ for nonresident fish. Spending the summer in the more productive fertilized zone of the experimental reach had no influence on survival despite higher productivity on all trophic levels and consistently higher growth rates in Arctic grayling. None of the environmental (stream temperature, discharge, winter severity, and incidence of drought) or population parameters (growth, condition factor, and mean fish size) that we examined explained significant amounts of variance in survival rates. The lack of responsiveness of survival to annual environmental conditions was unexpected and suggests that multiyear factors or life history tactics that maintain survival at the expense of growth and fecundity likely determine survival.
\end{abstract}

Résumé : Chez plusieurs espèces à forte longévité, telles que l'ombre arctique (Thymalus arcticus), le taux de croissance de la population est particulièrement sensible aux changements de probabilité de survie des adultes. La compréhension des facteurs qui contrôlent la survie des adultes chez cette espèce devrait fournir des perspectives sur la dynamique de population de cette espèce et d'autres espèces arctiques qui vivent longtemps. À l'aide du logiciel MARK, nous avons analysé des données de marquage-recapture étalées sur 17 années afin d'estimer les taux de survie des ombres arctiques de la rivière Kurapuk de 1985 à 2000. Les taux moyens annuels de survie varient dans l'ensemble de 0,39 à 1,0 ; ils sont en moyenne de $0,71 \pm 0,05$ pour les poissons résidants et de $0,75 \pm 0,05$ pour les non résidants. Le passage de l'été dans la section enrichie et plus productive de la zone expérimentale n'influence pas la survie, malgré une productivité accrue de tous les niveaux trophiques et des taux de croissance uniformément plus élevés chez l'ombre arctique. Aucune des variables examinées de l'environnement (température du cours d'eau, débit, rigueur de l'hiver, présence de sécheresses) ou de la population (croissance, coefficient de condition, taille moyenne des poissons) n'explique de partie significative de la variance des taux de survie. Ce manque de réaction de la survie aux conditions annuelles du milieu est inattendu et il laisse croire que la survie est déterminée par des variables ou des tactiques démographiques qui agissent sur plusieurs années pour maintenir la survie aux dépens de la croissance et de la fécondité.

[Traduit par la Rédaction]

\section{Introduction}

Understanding the factors influencing population growth is critical for fundamental understanding of populations and their impact on ecosystems as well as for managing species. Survival at multiple life history stages, development time, and fecundity all act in concert to determine population growth rates (Stearns 1992). The importance of survival in

Received 24 September 2003. Accepted 14 May 2004.

Published on the NRC Research Press Web site at

http://cjfas.nrc.ca on 23 December 2004.

J17761

K.M. Buzby ${ }^{1,2}$ and L.A. Deegan. The Ecosystems Center, Marine Biological Laboratory, Woods Hole, MA 02543, USA.

${ }^{1}$ Corresponding author (e-mail: karen.buzby@mail.wvu.edu).

${ }^{2}$ Present address: Department of Civil and Environmental Engineering, West Virginia University, Morgantown, WV 26506, USA. determining population growth rate has been demonstrated across several taxonomic levels for long-lived species in both modeling (Jonsson and Ebenman 2001) and metapopulation studies (Heppel et al. 2000; Sæther and Bakke 2000).

Survival rates reflect the interplay between changeable environmental conditions, population densities, and a varying population structure. Interannual climatic variation may play a direct or indirect role in survival either by stressing individuals or by affecting the food sources on which they are dependent. Catastrophic events such as floods or droughts often negatively affect survival rates (Lebreton et al. 1992). Overlaying the effects of a changing environment is the influence of the population on its own survival rates. Densityrelated reduction in survival rates has been attributed to increased competition (De Leo and Gatto 1996), displacement into marginal habitats (Frederiksen and Bregnballe 2000), and increased agonistic interactions (Wildy et al. 2001). Population survival rates may also be affected as the population structure changes owing to shifting sex ratios or the ad- 
vent of strong age-classes owing to sex- or age-specific mortality rates.

In severe environments, climatic conditions are harsh and resources are limited, and we expect a strong influence of environmental conditions on survival rates. Arctic streams on the North Slope of Alaska are severe environments where the growing season is perhaps 3 months followed by a 9month winter, which includes months of extreme cold and little to no sunlight. While much of the Arctic remains unstudied, the Kuparuk River, Alaska, has been the site of concentrated study over the last 20 years with the Arctic grayling (Thymallus arcticus) population under study since 1985. Deegan et al. (1999) have demonstrated high interannual variability in growth of Arctic grayling of the upper Kuparuk River. In addition, the Kuparuk River has been the site of a long-term fertilization experiment that has increased the productivity of the ecosystem and, in most years, has resulted in higher weight gains for Arctic grayling in the fertilized zone (Peterson et al. 1993; Deegan et al. 1999; Slavik et al. 2004). The higher productivity and growth might be expected to result in higher survivorship. This data set provides an excellent opportunity to examine the relative roles that environmental factors and population structure play in survival dynamics of an Arctic fish owing to the length of the study and the breadth of information about the ecosystem.

\section{Methods}

\section{Study site}

This study was performed in the Kuparuk River $\left(68^{\circ} 38^{\prime} \mathrm{N}\right.$, $149^{\circ} 24^{\prime} \mathrm{W}$ ), a meandering tundra stream that originates in the foothills of the Brooks Range, Alaska, and flows north several hundred kilometres to the Arctic Ocean. Much of the study was concentrated in a $5-\mathrm{km}$ experimental reach bisected by the Dalton Highway (Fig. 1). At this point, the Kuparuk River is a fourth-order river consisting of alternating riffles $(10-50 \mathrm{~cm}$ in depth) and pools $(1.5-5 \mathrm{~m})$ with a mean width of $20 \mathrm{~m}$ and bottom substrates composed of rocks and cobble (Hershey et al. 1997; Slavik et al. 2004).

The experimental reach of the Kuparuk River has been the site of a long-term phosphorus fertilization experiment initiated in 1983. Each summer, low levels of phosphorus are added to the downstream section of the experimental reach. The location of the phosphorus dripper has changed over the years so that recovery from fertilization could be studied. The original kilometre designations and the locations of the approximately $1.5-\mathrm{km}$ fish capture sections of the reference $(-1.3-0.0 \mathrm{~km})$ and fertilized zones $(2.0-3.5 \mathrm{~km})$ have remained the same and are referenced to the site of the original 1983 dripper. The phosphorus addition has resulted in increased primary production, macroinvertebrate production, and often fish growth in the fertilized zone of the river (Deegan and Peterson 1992; Peterson et al. 1993). However, environmental factors such as stream temperature and discharge have larger effects on fish growth than phosphorus fertilization (Deegan et al. 1999).

Arctic grayling are the only fish found in the experimental reach of the Kuparuk River as well as further upstream and downstream at least $50 \mathrm{~km}$. Most of the fish in this study spend the winter in Green Cabin Lake about $25 \mathrm{~km}$ upstream of the experimental reach, the outlet of which forms the source of the Kuparuk River. After ice-out (mid-May), Arctic grayling leave the lake and spawn and by early July have redistributed themselves to their summer feeding territories where they remain until early to mid-August. In early August, the combination of decreasing day length and high river discharge initiates the overwintering migration to Green Cabin Lake. The migration is usually completed by late September.

\section{Field sampling}

Each summer since 1985, fish in the experimental reach have been captured through angling and seining. In most years, there were two 2-week capture periods each year: one in early July and a second in early August focused in 1.5-km sections of each zone. Each year, we attempted to capture at least 100 fish in each zone in July and to recapture at least 50 of these fish again in August. Fish caught in July were considered summer residents, that is, fish that had established feeding territories within the experimental reach. Fish caught in August consisted of summer residents as well as nonresident fish that were migrating through the reach on their way to overwintering sites. For the purposes of the mark-recapture analysis, we made no distinction between capture periods, as they were only 3 weeks apart and treated both as one capture session. Sampling intensity was variable over the years and we never attempted to capture all of the fish in the reach.

Captured fish were held overnight in holding pens close to the capture location. All captured fish were anesthetized with tricaine methanesulfonate (MS 222), weighed ( $\pm 2 \mathrm{~g})$, and total length (TL) measured $( \pm 0.5 \mathrm{~cm})$. Tag information from previously marked fish was recorded and any unmarked fish was given a unique tag. Only fish larger than $29 \mathrm{~cm}$ were tagged and therefore constitute the adult population. All fish were released. Tagging methods have changed over the study. From 1985 to 1993, all fish were tagged with an anchor tag. Between 1993 and 1997, many fish were double-tagged with an anchor tag and a passive integrated transponder (PIT) tag, and some fish were tagged with anchor tags only for comparison. Since 1998, we have been tagging fish with PIT tags only based on analysis of the double-tagged fish, which demonstrated higher long-term retention of PIT tags (Buzby and Deegan 1999).

We attempted to prevent fish from leaving the reach before they were recaptured by installing one to four weirs, depending on the year. The weirs remained in place for the entire summer unless large storm events, which occur from zero to four times per summer, knocked down the weirs. The weirs remained down for 24-48 h in most cases or occasionally several days if water levels remained high. If the storm event occurred in early August, the fish often left the reach to migrate upstream to overwintering sites.

In some years (1987, 1989, 1990, 1992, 1995, and 1999), the autumnal migration into Green Cabin Lake, the main overwintering site, was monitored. In 1988 and 1990, the spring out-migration from the lake was also monitored. A weir was placed across the outlet of the lake preventing movement in or out of the lake. The Arctic grayling were captured using a seine as they collected at the weir. Captured fish were anesthetized, weighed, measured, and tagged in the same manner as in the experimental reach. For the pur- 
Fig. 1. Map of the study region in Alaska showing the location of the Kuparuk River on the north slope as well as the study site on the Kuparuk River. The Dalton Highway bisects the 5-km (K) experimental reach. The fertilized reach of the river extends from 2.0 through $3.5 \mathrm{~km}$ and the reference reach is considered to extend from 0.5 to $-1.0 \mathrm{~km}$. Current and historical locations of the phosphorus dripper as well as weir locations are noted. Green Cabin Lake, the main overwintering site, is approximately $25 \mathrm{~km}$ from the experimental reach.

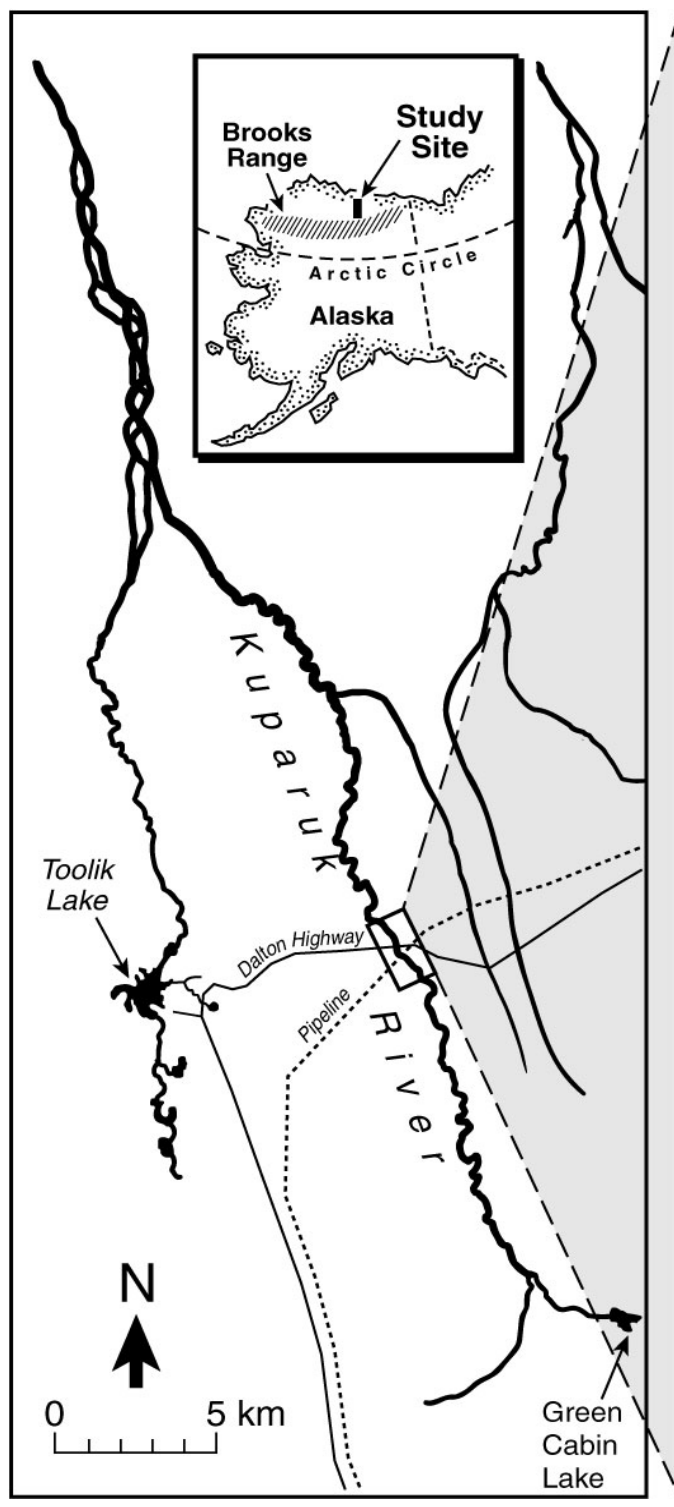

poses of the mark-recapture analysis, first-time captures within the experimental reach of fish that had been marked at the lake were considered unmarked.

\section{Data analysis}

We analyzed the mark-recapture data set with several models available within the program MARK (White and Burnham 1999). All are extensions of the Cormack-JollySeber model, which in its basic form estimates group- and time-dependant survival and recapture rates. A major strength of Cormack-Jolly-Seber models is that unlike other methods used to estimate survival, they are able to separate recapture probabilities from survival estimates (Lebreton et al. 1992). Survival estimates were made using Barker's extension of Burnham's model, which jointly analyzes live re- captures and tag recoveries (Barker 1999). Barker's model incorporates resighting data between capture occasions, which improves the precision of the survival estimates. In addition to estimating survival and recapture probabilities, it also estimates five additional parameters that describe resighting and risk of capture probabilities: $r$, the probability of resighting a dead fish; $R$, the probability of being resighted and surviving; $R^{\prime}$, the probability of being resighted and then dying; $F$, the probability of being at risk of capture at times $t$ and $t+1$; and $F^{\prime}$, the probability of not being at risk of capture at time $t$ but at risk during time $t+1$.

The $r$ parameter was set to zero because there were no resightings of dead fish. Resighting parameters ( $R$ and $R^{\prime}$ ) were set to zero (and therefore not estimated) except in years when the autumnal migration into Green Cabin Lake was 
monitored. Parameters were estimated using numerical maximum likelihood techniques and are reported as estimates \pm SE.

We divided the data set into two groups: residents and nonresidents. We believed that residents would have higher recapture rates than nonresidents and that recapture rates might vary depending on when the autumnal migration started. We could not differentiate between resident and nonresident fish once the autumnal migration had started because at that time, they would be captured within the same locations in the river. The start of the autumnal migration, which can be identified because fish alter their behavior and begin to collect behind the weirs, has never begun prior to 1 August. Therefore, we defined residents as those fish that were captured before 1 August and nonresidents as those captured on or after 1 August. Undoubtedly, some fish were misclassified. The most likely misclassification was that resident fish would be classified as migrant. However, since we were most interested in resident fish and the numbers of nonresidents were often an order of magnitude greater than those of the residents, we felt that this criterion would give us the most information about the residents without being overwhelmed by the nonresidents.

Program MARK was used to model survival over a 16year period. A bootstrap goodness-of-fit test included within program MARK was done to ensure that the general model fit the data. The general model generates estimates for seven parameters for each group and year, many of which are essential to running the model correctly but were of little interest in this study. For this data set, the general model estimates 230 parameters. Once we had determined that the general model fit the data, we used an iterative procedure to determine if all parameters within the general model were group or time dependent. Any that were not group or time dependent could then be condensed to a single parameter. We used Akaike's information criterion (AIC) as the criterion to determine the best fitting model. AIC balances the increased precision of parameter estimates through the reduction in the number of parameters against the reduced fit of the model to the data as the number of parameters are reduced (Burnham and Anderson 1998). The difference in AIC ( $\triangle \mathrm{AIC}$ ) between models that are being compared is then used to calculate an Akaike weight $(\exp (-0.5 \Delta \mathrm{AIC}) / \mathrm{sum}$ of $\exp (-0.5 \Delta \mathrm{AIC}))$ for all models. The ratio of the Akaike weight of the model being examined to the Akaike weight of the best model gives the model likelihood (Burnham and Anderson 1998).

Once the best model was found, we examined whether a variety of environmental and population parameters could be used to predict survival better than the reduced general model. We used summer stream temperatures determined as the mean over the period from 1 July to 14 August of each year. Mean, maximum, and minimum summer discharges were determined over the same time period. Drought years were defined as those years with periods of low discharge (below the 25 th percentile) for 15 days or longer. At these low discharges, pools become isolated as riffles become dry. In 1988 the mean daily discharge was $0.48 \mathrm{~m}^{3} \cdot \mathrm{s}^{-1}$ for 32 days, in 1993 the daily discharge averaged $0.69 \mathrm{~m}^{3} \cdot \mathrm{s}^{-1}$ for 16 days, in 1990 the daily discharge averaged $0.31 \mathrm{~m}^{3} \cdot \mathrm{s}^{-1}$ for more than 59 days, and in 1998 the daily discharge was $0.61 \mathrm{~m}^{3} \cdot \mathrm{s}^{-1}$ for
25 days. Daily temperature and discharge plots may be found in Deegan et al. (1999) and Slavik et al. (2004). Of all of the environmental conditions that we used, only mean and maximum discharges were correlated (Pearson's correlation coefficient $=0.66, p<0.01)$. Environmental variables are presented as means $\pm \mathrm{SE}$.

We used two measures that evaluate the influence of the summer feeding period: summer growth (calculated as the mean difference in weight for individuals captured in July and August and adjusted for initial weight and time at large, grams per gram per day) and late-season fish condition factor (Fulton-type $K_{\mathrm{TL}}=1000\left(\right.$ weight $(\mathrm{g}) \times$ total length $\left.(\mathrm{cm})^{-3}\right)$ ). We used a Fulton-type condition factor because the lengthweight power regression ( $n=9287,10-45 \mathrm{~cm}$ TL) has shown the exponent to be near $3( \pm 0.03)$ for Arctic grayling and the size range that we were comparing is small (29$45 \mathrm{~cm} \mathrm{TL})$. Because fish condition factor and summer growth were used as indicators of the unfertilized river, they were calculated from data from reference zone fish only. Summer growth is a precise measure of fish performance but was drawn from a small sample of fish (10-20 fish per year) from a relatively restricted section of the river $(1.5 \mathrm{~km}$ of the reference zone). Condition factor, a less precise measure than summer growth, was calculated from a much larger sample of fish (40-80 fish per year) that ranged over a larger section of river. Late-season condition factor (fish captured after 1 August) was used to assess stream growth conditions for that summer. Mean summer growth and mean late-season condition factor were not correlated (Pearson's correlation coefficient $<0.32, p>0.12, n=18$ ).

As a gauge of winter severity, we used the number of days after 1 May that it took for the snow pack to disappear, which corresponds to the date that flow resumes in the Kuparuk River and Arctic grayling leave their overwintering sites. Early-season condition (fish captured before 11 July) was used as a combined measure of previous winter severity and the previous summer performance. We were missing data for stream temperature and summer growth in 1987, so for these factors, we used only the mark-recapture data from 1988 through 2000. There were notable differences in mean length of residents and nonresidents in many years, so we examined the influence of length on survival for residents and nonresidents separately. The sex or age of Arctic grayling can only be determined on dead fish, so these factors were not included in our analysis.

Survival was estimated for the time between observation periods, from summer to summer. The parameters detailed above were evaluated for their ability to predict survival for the year following the one in which they were measured. That is, a parameter such as stream temperature measured in the summer of 1995 would be evaluated for its ability to predict survival for the year between the summer of 1995 and the summer of 1996. Two parameters, winter severity and early-season condition, were evaluated for their ability to predict survival in the year before the year in which they were measured. For example, winter severity or early-season condition factor measured in the spring of 1996 would be evaluated for its effect on survival from the summer of 1995 to the summer of 1996.

We used the multistrata model (also within program MARK) to assess whether survival differed between the fertilized and 
reference zones of the experimental reach, as our data were too sparse to use Barker's model. The multistrata model was developed to assess individual site fidelity and the impact that fidelity might have on survival and recapture. It estimates survival, recapture, and transition probabilities. Only resident fish were used in this analysis, as they spent the summer in either the reference or fertilized zone of the river. The multistrata model does not use resighting data; however, it does require information about where the fish was captured. Generally, in any given year, Arctic grayling remained in either the reference or the fertilized zone all summer. In those cases where an individual was caught in both zones in the same year, the first capture site was used as the primary summer residence. The second capture was usually during the autumnal migration.

\section{Results}

Of the 5623 individual Arctic grayling used in this analysis, 2901 were captured more than once during the 17 years of the study. We classified 1948 fish as summer residents within the experimental reach and 3675 as nonresidents. Most fish $(72 \%)$ were in the medium size range $(33-38 \mathrm{~cm}$ TL) (Fig. 2). Small fish (29-32 cm TL) comprised 11\% and large fish $(39+\mathrm{cm}$ TL) $18 \%$ of the population. Both residents and nonresidents underwent substantial changes in their population size structure over time. There were two periods (19901993 and 1997-1999) during which mean length of the population declined considerably. This corresponded to an increase in fish previously smaller than our cutoff of $29 \mathrm{~cm}$ TL recruiting into our target population (Fig. 2). The size change and recruitment were evident in the nonresident population about a year earlier than in the resident population.

Over the 17 years of this study, Arctic grayling were exposed to climatic conditions that varied by $1.5-30$ times among years (Table 1). Mean annual stream temperature during the summer varied by a factor of 1.5 (range 8.3$12.9{ }^{\circ} \mathrm{C}$, overall annual average of $9.78 \pm 0.32{ }^{\circ} \mathrm{C}$ ). Minimum discharge varied by a factor of 5 (range 0.20 $1.01 \mathrm{~m}^{3} \cdot \mathrm{s}^{-1}$, mean $0.51 \pm 0.06 \mathrm{~m}^{3} \cdot \mathrm{s}^{-1}$ ) among years, while maximum discharge varied by a factor of 30 (range 1.31$38.16 \mathrm{~m}^{3} \cdot \mathrm{s}^{-1}$, mean $14.27 \pm 2.32 \mathrm{~m}^{3} \cdot \mathrm{s}^{-1}$ ). As expected, average river discharge (range $0.3-4.4 \mathrm{~m}^{3} \cdot \mathrm{s}^{-1}$, mean $2.52 \pm 0.27 \mathrm{~m}^{3} \cdot \mathrm{s}^{-1}$ ) was less variable (factor of 15) than maximum discharge but more variable than minimum discharge. Winter severity varied between 12 (river flow begins 12 May) and 40 days (10 June) with a mean of $24.9 \pm 2.3$ days.

Fish growth and condition also differed widely among years (Table 1). Summer growth varied by a factor of 30 (range from a low of $0.3 \times 10^{-3} \mathrm{~g} \cdot \mathrm{g}^{-1} \cdot \mathrm{day}^{-1}$ in 1990 to a high of $4.74 \times 10^{-3} \mathrm{~g} \cdot \mathrm{g}^{-1} \cdot \mathrm{day}^{-1}$ in 1991 , mean annual average $\left.2.63 \pm 0.43 \mathrm{~g} \cdot \mathrm{g}^{-1} \cdot \mathrm{day}^{-1} \times 10^{-3}\right)$. Early-season condition factor was lower (range 7.56-9.12, mean $8.08 \pm 0.09$ ) than lateseason condition factor (range 8.09-9.47, mean 8.67 \pm 0.08 ), but variation among years was about the same (factor of 1.2).

\section{Resident fish: fertilized versus reference zone survival}

The multistrata model analysis suggested that Arctic grayling that summered in the fertilized zone had a probability of survival similar to that of those that summered in the reference zone (Table 2). The most parsimonious model (i.e.,
Fig. 2. Size distribution of $(a)$ residents and $(b)$ nonresidents in the experimental reach from 1985 to 2000 . The data were divided into small (29-32 cm total length (TL)) (open bars), medium (33-38 cm TL) (hatched bars), and large fish (39+ cm TL) (solid bars). Mean \pm SE lengths (circles) of residents and nonresidents in each year are also given.

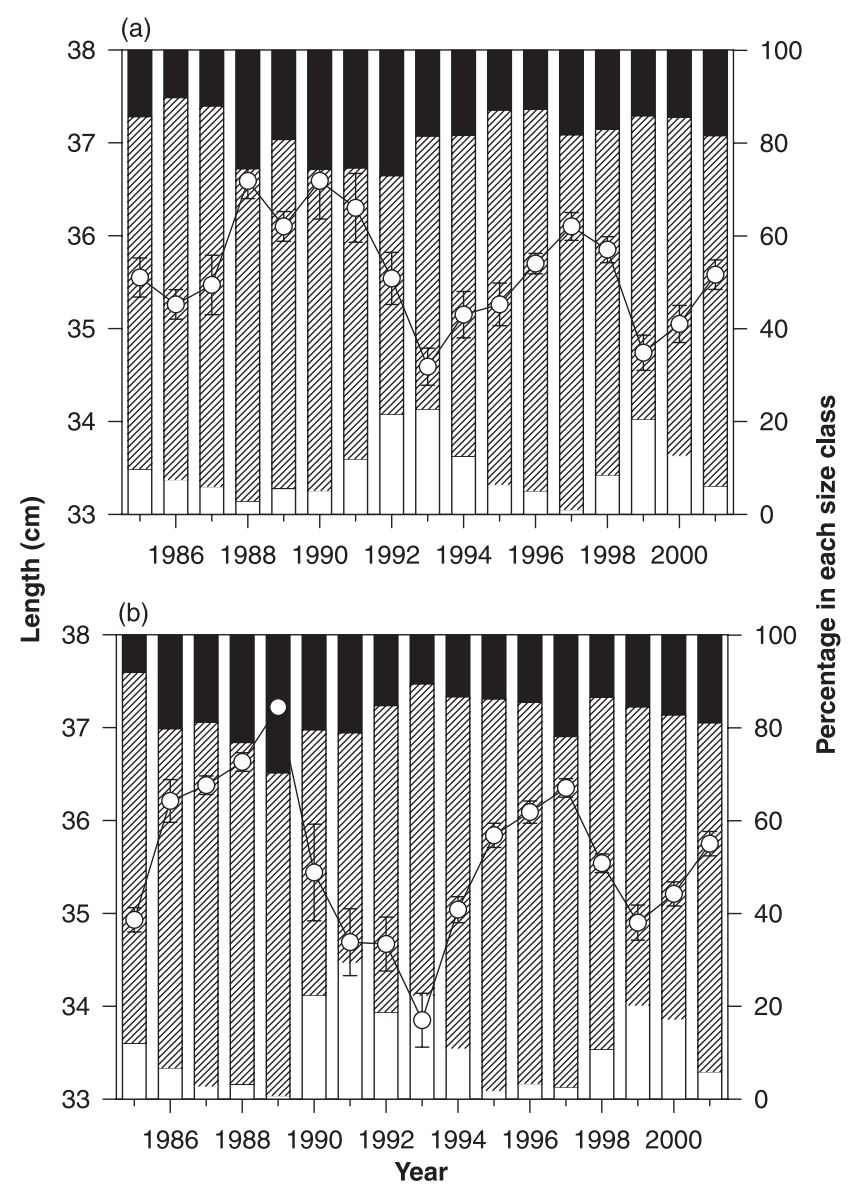

the one that best described the data with the fewest parameters) suggested that survival and recapture probabilities varied among years but not between reference and fertilized groups and transition probabilities varied between years and groups (Table 2). The probability of moving from the reference to the fertilized zone $(0.15 \pm 0.03)$ was very similar to that of moving from the fertilized to the reference zone $(0.14 \pm 0.05)$ but did vary among years. Because the fertilization did not affect survival rate, all fish, regardless of the zone that they spent the summer in, were combined in subsequent analyses.

\section{Entire population}

The most parsimonious resighting model suggested that annual survival differed among residents and nonresidents (group) and that survival varied annually (year) (Table 3). The resighting parameters $R$ and $R^{\prime}$ and the fidelity parameter $F$ were also group and year dependent (Table 3 ). Modeling recapture probabilities as variable between years but not between groups and modeling the fidelity parameter $F^{\prime}$ as constant for residents and variable over time for nonresidents improved model fit. 
Table 1. Parameters that were used to assess the influence of environmental variables or fish growth or condition on adult Arctic grayling survival in the Kuparuk River.

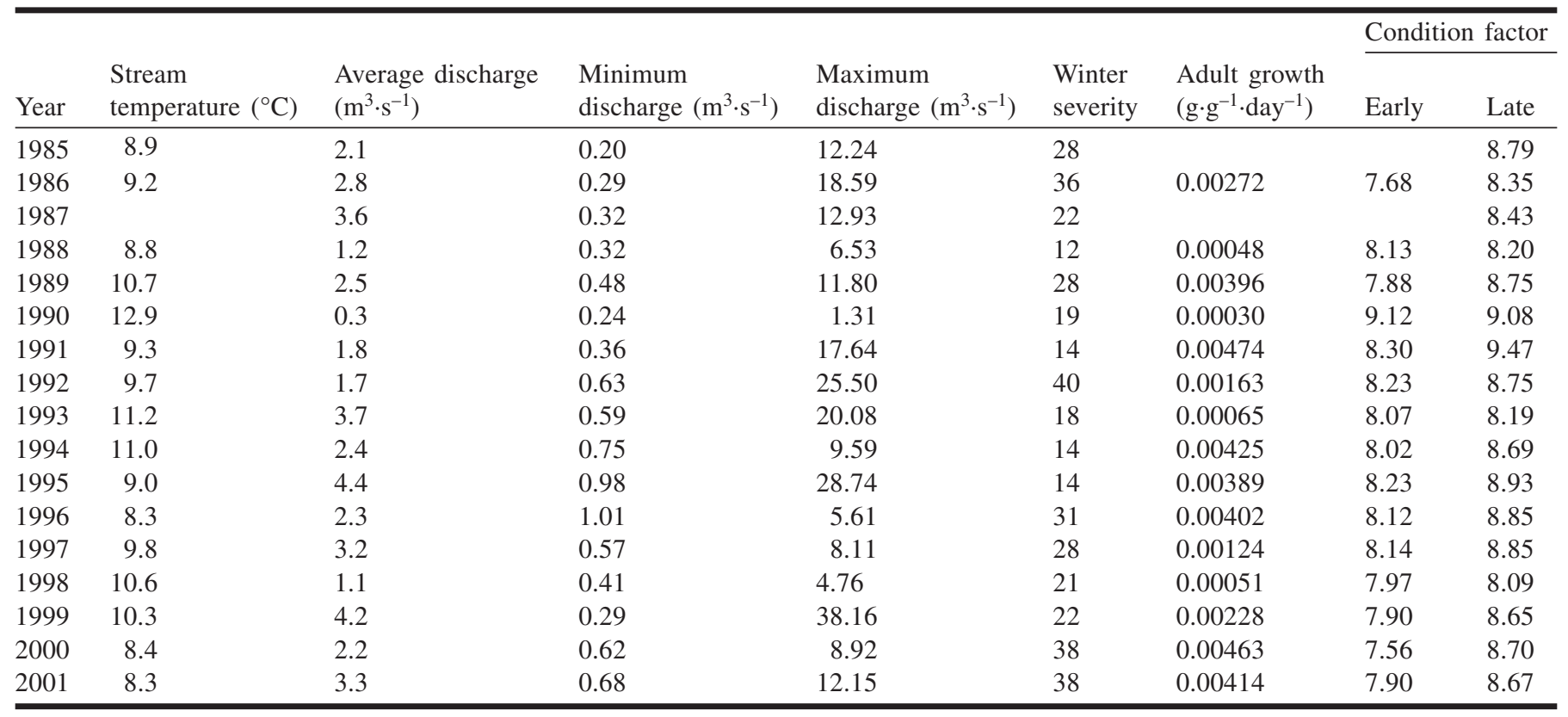

Note: Values for stream temperature and average discharge are summer means (1 July - 14 August). Data were not available for all years.

Table 2. Multistrata model used to generate survival $(\Phi)$, recapture $(\rho)$, and transition $(\Psi)$ probabilities for fish in the fertilized and reference zones of the Kupauk River.

\begin{tabular}{lllll}
\hline Hypothesis tested & Model & AIC $^{a}$ & Akaike weight & Model likelihood \\
\hline Effect of group on survival and recapture & $\boldsymbol{\Phi}(\boldsymbol{t}) \boldsymbol{\rho}(\boldsymbol{t}) \Psi(g \times t)$ & 4885 & 0.880 & 1.000 \\
Effect of group on survival & $\boldsymbol{\Phi}(\boldsymbol{t}) \rho(g \times t) \Psi(g \times t)$ & 4889 & 0.116 & 0.130 \\
Effect of group on recapture & $\Phi(g \times t) \boldsymbol{\rho}(\boldsymbol{t}) \Psi(g \times t)$ & 4896 & 0.005 & 0.005 \\
Time dependent & $\boldsymbol{\Phi}(\boldsymbol{t}) \boldsymbol{\rho}(\boldsymbol{t}) \mathbf{\Psi}(\boldsymbol{t})$ & 4896 & 0.000 & 0.000 \\
Fully parameterized & $\boldsymbol{\Phi}(\boldsymbol{g} \times \boldsymbol{t}) \boldsymbol{\rho}(\boldsymbol{g} \times \boldsymbol{t}) \mathbf{\Psi}(\boldsymbol{g} \times \boldsymbol{t})$ & 4904 & 0.000 & 0.000 \\
Effect of group on transition between zones & $\Phi(g \times t) \rho(g \times t) \mathbf{\Psi}(\boldsymbol{t})$ & 4909 & 0.000 & 0.000 \\
\hline
\end{tabular}

\footnotetext{
Note: Alternative models were compared with the fully parameterized model (in bold). The parameter or parameters being investigated are in bold. $t$, time; $g$, group. Interaction is denoted with a times symbol $(\times)$.

${ }^{a}$ Akaike information criterion.
}

Overall annual survival rates were very similar between residents (range 0.45 and 1.0 , mean $0.71 \pm 0.05$ ) and nonresidents (range 0.39 and 1.0 , mean $0.75 \pm 0.05$ ) over the 15 year period, despite differences in the pattern with year (Fig. 3). In some years, especially between 1995 and 1999, survival rates of both residents and nonresidents were very similar; however, overall there was little correlation in survival rates between the two groups within a year (Pearson's correlation coefficient $=0.18, p=0.53, n=15$ ). Estimates generated with the resighting model were also similar to those generated by the multistrata model, especially in the latter half of the study (Fig. 4).

Recapture rates varied between 1.0 and 0.21 , with a steady downward trend over the study period (Fig. 5), but did not differ between resident and nonresident fish. The precision in the estimates has improved throughout the study, especially the period from 1994 to 1999 when fish were tagged with both anchor and PIT tags.

Resighting rates were variable between years and between resident and nonresident fish. The value of $R$ (the probability of being resighted and surviving) was higher for all time pe- riods for nonresidents $(0.57 \pm 0.06)$ than for resident fish $(0.44 \pm 0.07)$. Estimates of $R^{\prime}$ (the probability of being resighted and then dying before the next capture period) were anomalously high in 1987 for residents (1.00) and in 1992 for nonresidents $(0.60)$ but were low $(<0.38)$ for all other time periods.

The fidelity parameters $F$ (the probability that an animal is at risk of capture during times $i$ and $i+1$ ) and $F^{\prime}$ (the probability that an animal not at risk at time $i$ is at risk during time $i+1$ ) describe migration in and out of the study area. In most years, parameter estimates of $F$ approached 1 and $F^{\prime}$ was estimated at $0.12 \pm 0.02$ for the residents, which is consistent with permanent emigration for that year. Estimates of $F^{\prime}$ were low for the nonresidents; however, estimates of $F$ were highly variable. This may reflect variability in sampling effort combined with flood events that knock the weirs down releasing fish before they can be recaptured.

Incorporation of environmental factors (stream temperature and discharge) that strongly influence summer growth (Deegan et al. 1999) did not improve model fit (Fig. 6). Reasoning that perhaps only the most severe conditions affected 
Table 3. Resighting models examined to estimate survival rates.

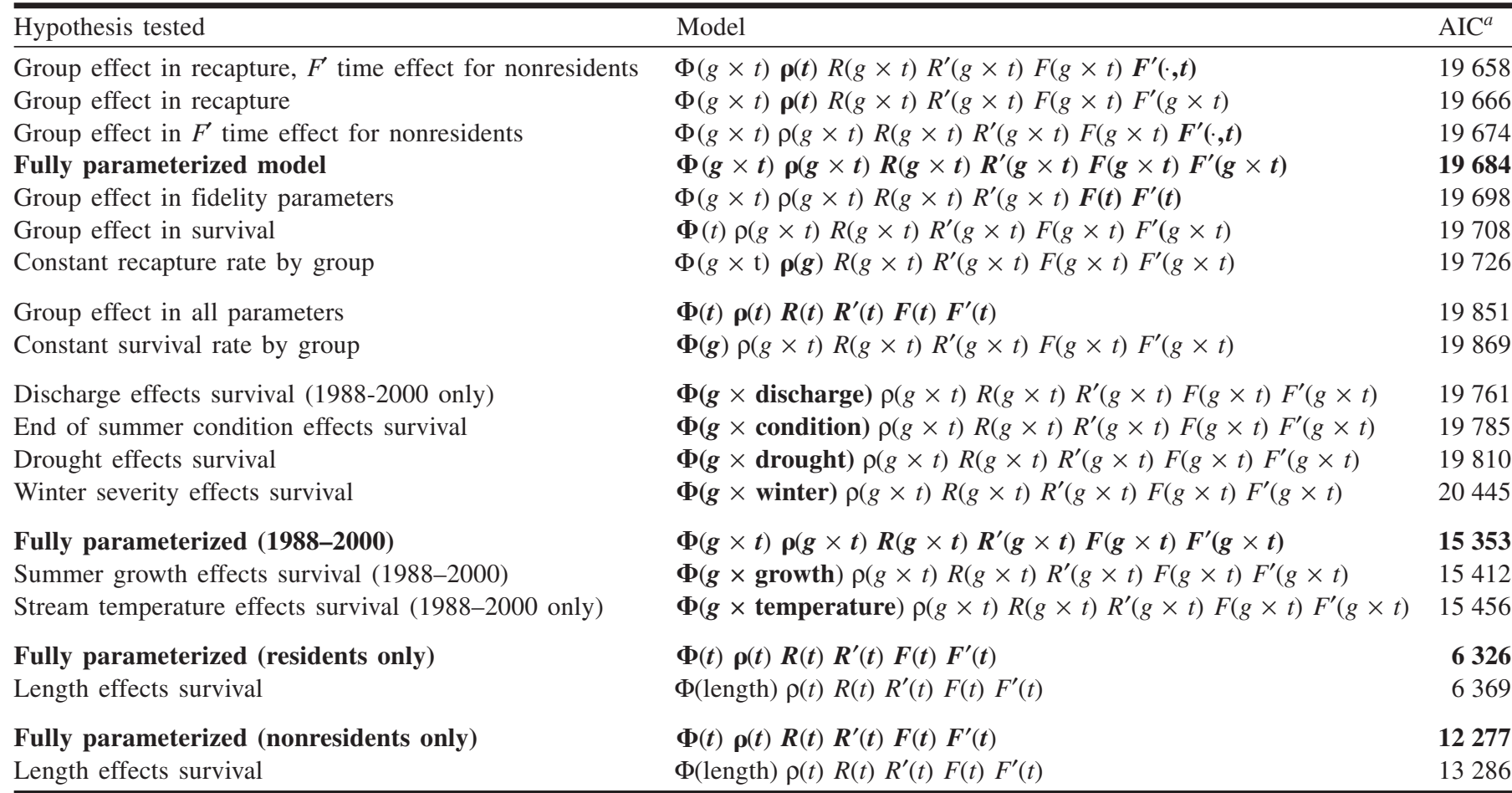

Note: The resighting model estimates seven parameters: $\Phi$, survival; $\rho$, recapture; $r$, recovered dead; $R$, resighted and survived; $R^{\prime}$, resighted and died; $F$, at risk of capture in year $i$ and year $i+1 ; F^{\prime}$, not at risk of capture in year $i$ but at risk in year $i+1 ; t$, time; $g$, group. Interaction is denoted with a times symbol $(\times)$. Alternative models were compared with the fully parameterized model (in bold) using either the entire data set (1985-2000) or a partial data set (1988-2000) when data were lacking. Results are shown for those models that best fit the data. The data set was divided into residents and nonresidents to examine the effect of length because there were significant differences between the populations for this covariate. The parameter or parameters being investigated in the alternative models are in bold.

${ }^{a}$ Akaike information criterion.

Fig. 3. Annual survival estimates $( \pm \mathrm{SE})$ for residents (solid circles) and nonresidents (open circles). As the capture and release period is during the summer, estimates are for the period from one summer to the next.

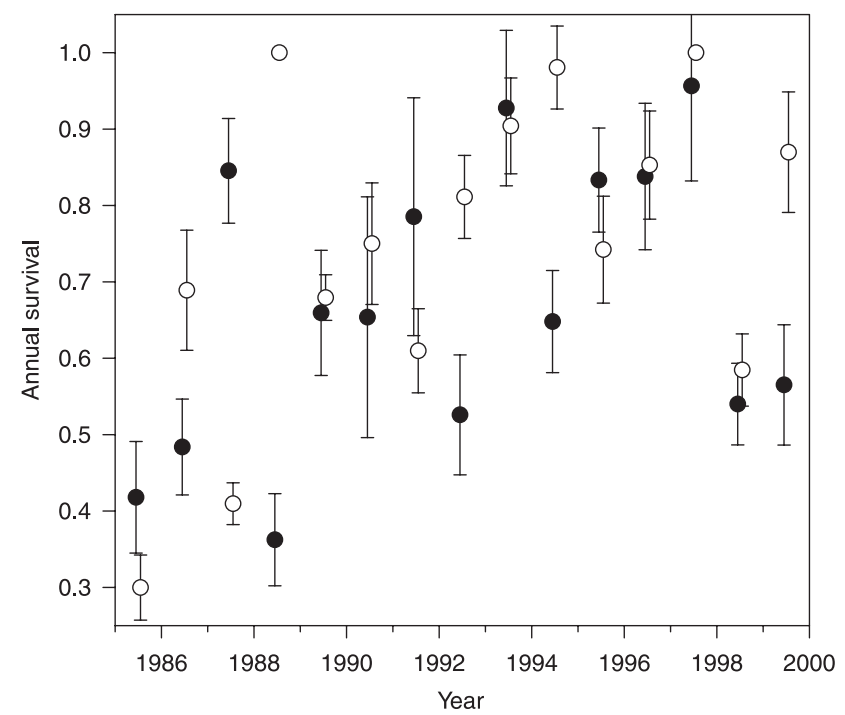

survival, we tested whether drought or nondrought years or winter severity affected survival. Neither of these factors improved our ability to predict survival.
Fig. 4. Comparison of annual survival rate estimates generated by the resighting (solid circles) and multistrata models (open circles).

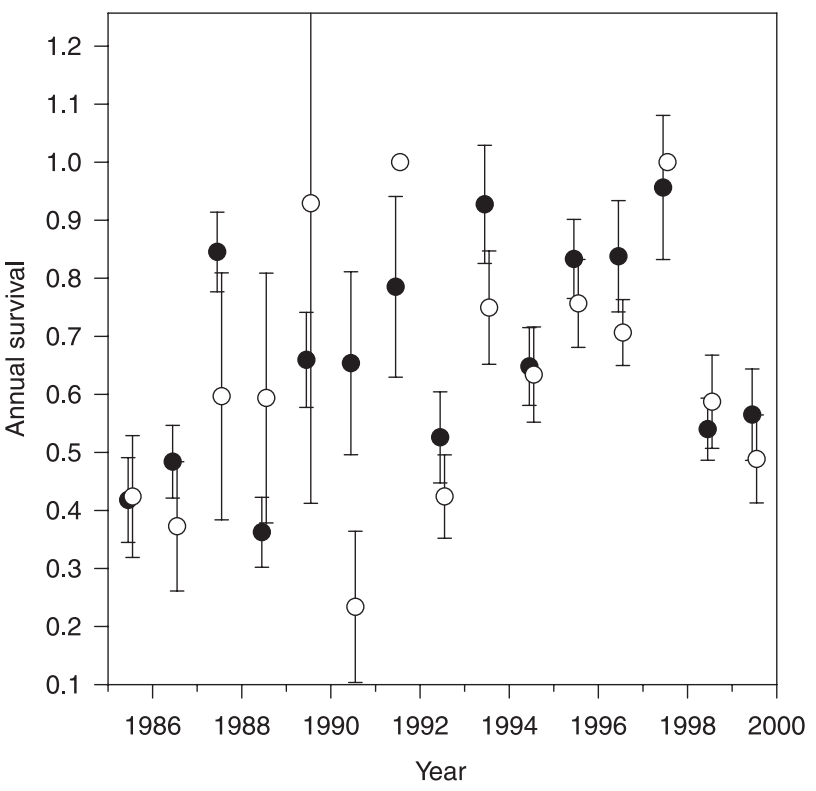

None of the aspects of fish population (growth, earlyseason or late-season condition, or fish length) improved the fit of the model to survivorship (Table 3). Length was a 
Fig. 5. Annual recapture estimates for each year of the study. The combined recapture estimate is given here, since there was no significant difference in recapture rates between residents and nonresidents.

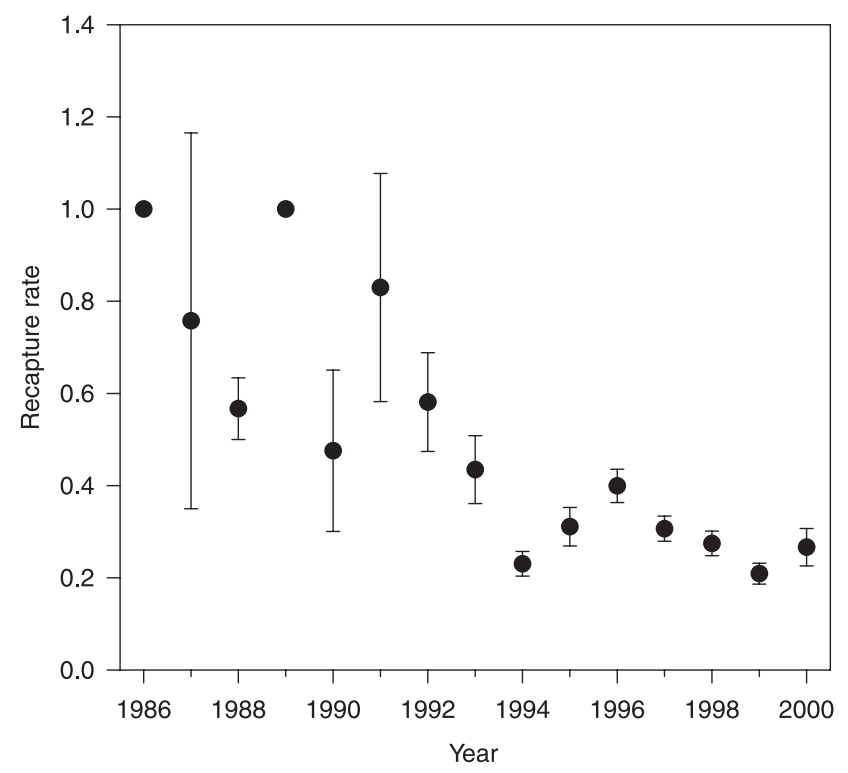

better estimator of survival for residents than for nonresidents; however, it did not fit the data better than the fully parameterized model.

\section{Discussion}

Overall, our estimates of annual survival of Arctic grayling ( 0.71 for residents and 0.75 for nonresidents) are very similar to Clark's (1992) estimate of 0.69 for the more southerly Arctic grayling population in the Chena River, Alaska. None of the parameters used to quantify environmental conditions or the ability of fish to acquire resources were sufficiently important to survival dynamics to improve the fit of the model to the data. In keeping with these results, there was no significant difference in survival between fish that spent the summer in the reference and fertilized zones of the river despite greater food resources and higher weight gain in fish that summered in the fertilized zone.

On an individual basis, larger fish generally have higher survival rates because of their ability to hold better territories (Hughes 1992), evade predation, and have higher energy reserves to withstand overwintering conditions (Cargnelli and Gross 1997; Sogard and Olla 2000). As there were substantial changes in the size structure of the population, we expected there to be a relationship between fish size and survival but were unable to demonstrate this. Our study considered only adult fish (29-42 cm TL, with most fish $<40 \mathrm{~cm}$ TL) and may not have included a wide enough range of values for size effects to be detected.

Density of fish has been suggested to affect survival rates through competition for resources, increased agonistic interactions, and higher predation risk as individuals are forced into more marginal habitats. Oxygen availability may be a limiting factor in these Arctic lakes that are frozen for 9 months of the year and increased densities may induce hypoxic conditions in overwintering sites. We could not di- rectly assess whether there were density-dependent effects on survival rates because we lack information about fish densities in the river or in the overwintering lake. However, since it takes at least 5 years for young-of-the-year Arctic grayling to recruit into the adult population, we can surmise that in years when survival is poor the population declines and when survival is good the population is constant or increases. There were few years when both survival and recruitment were high; however, a recruitment episode occurred between 1990 and 1994. Resident survival rates were variable over this period; nevertheless, it should be noted that one of the highest survival rates was recorded in 1994. Nonresident survival rates steadily increased during this period. While not conclusive, this indicates that at densities commonly found in the Kuparuk River, it is unlikely that density-dependent factors play a role in survival dynamics.

Surprisingly, there were significant differences in survival rates between fish that were summer residents in the experimental reach and nonresidents that spent the summer downstream of the experimental reach and were caught as they migrated upstream to overwintering sites. Some of this difference may be the result of slight differences in tag loss between the two groups. From 1985 through 1992, fish were tagged with external anchor tags. Retention of these tags is high for the first several years after tagging; however, it decreases dramatically after the tags have been in place for more than 3 years (Buzby and Deegan 1999). The number of resident and nonresident fish tagged in each year was highly variable between the two groups as well as between years, which would lead to differing probabilities in tag loss between the two groups. Mark-recapture methods are unable to differentiate between tag loss and mortality; therefore, differing tag loss probabilities would be superimposed on survival rates. The different tag loss rates between residents and nonresidents are probably causing the perceived differences in survival rate estimates. Bolstering this argument is the convergence in survival rates in the last several years when we were tagging fish with both PIT and anchor tags. The probability that a fish will lose both tags is extremely low, virtually eliminating errors due to tag loss.

The effects of tag loss extend beyond creating variability in survival rate estimates; it undoubtedly caused us to underestimate survival rates. We estimate that in most years, between 10 and 20 fish were not seen because of tag loss. While the uneven distribution of tag loss between residents and nonresidents caused the model to accept the argument that differences between the two groups were significant, the overall effect of tag loss on survival rates was probably minor.

The lack of any single or combination of factors that correlated well with survival may have occurred for several reasons. Our approach evaluated environmental parameters that have been suggested to influence survivorship; however, we may not have used a good surrogate for that factor or we may not have had data pertaining to the critical factor. For example, we lack information on predation rates and on the populations of the predators, one of the major causes of adult mortality identified by Wootton (1998). However, we expected that in years when resources are adequate or plentiful, fish would be less vulnerable to predation and that this might have been reflected in the measures that we used. 
Fig. 6. Relationship between environmental variables thought to influence survival and annual survival rates for residents (solid circles) and nonresidents (open circles).

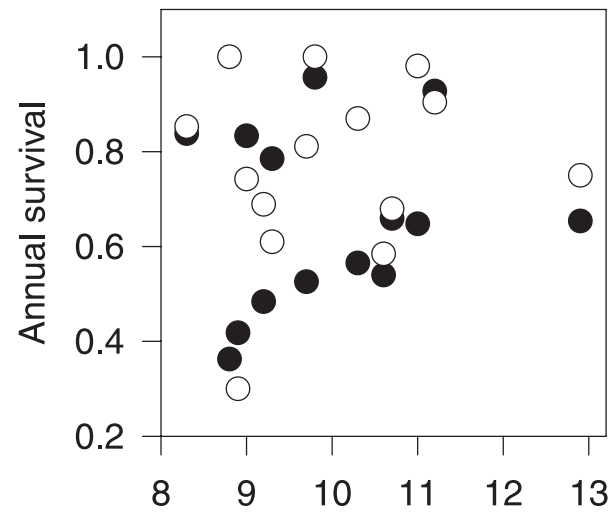

Summer stream temperature $\left({ }^{\circ} \mathrm{C}\right)$

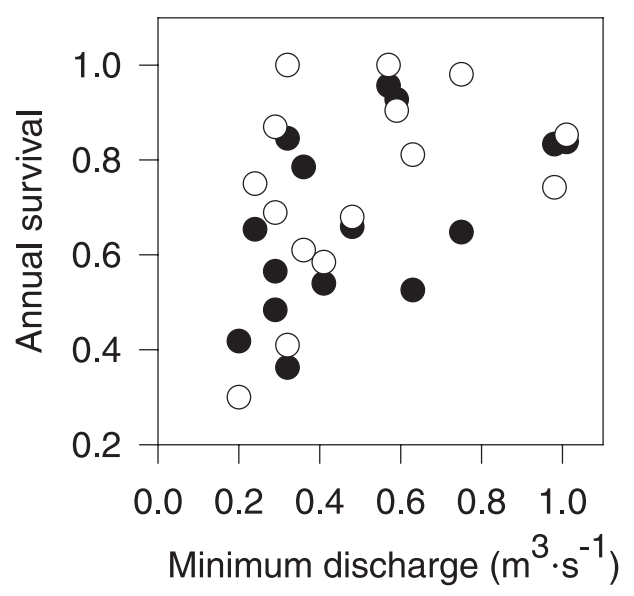

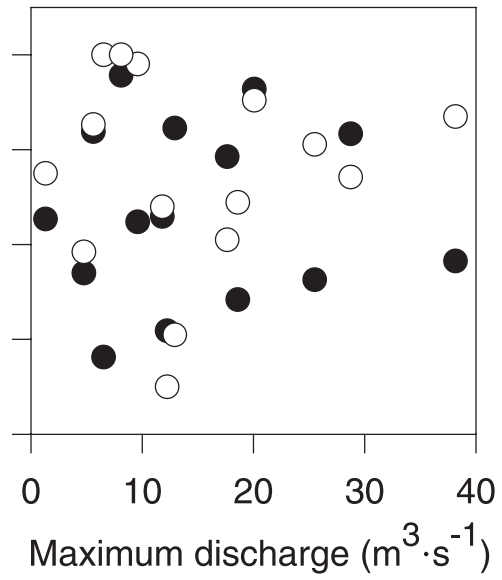

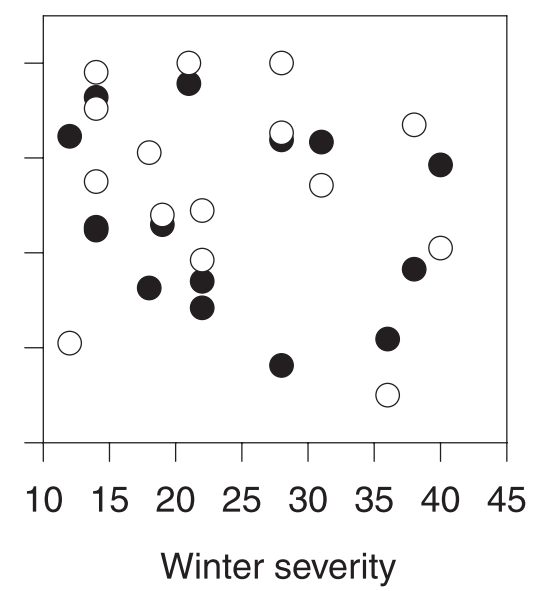

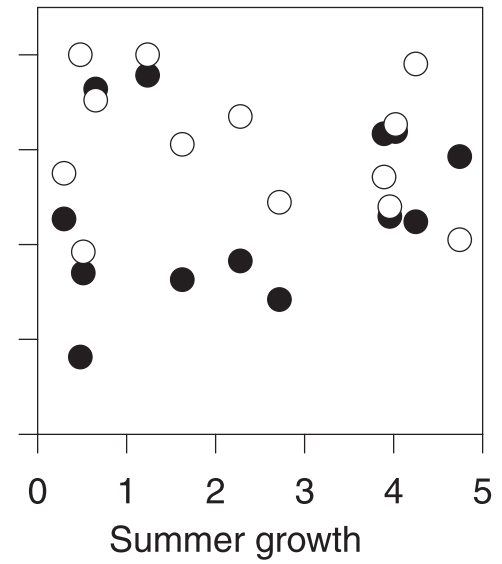

$\left(g \cdot g^{-1} \cdot\right.$ day $\left.^{-1}\left(\times 10^{-3}\right)\right)$

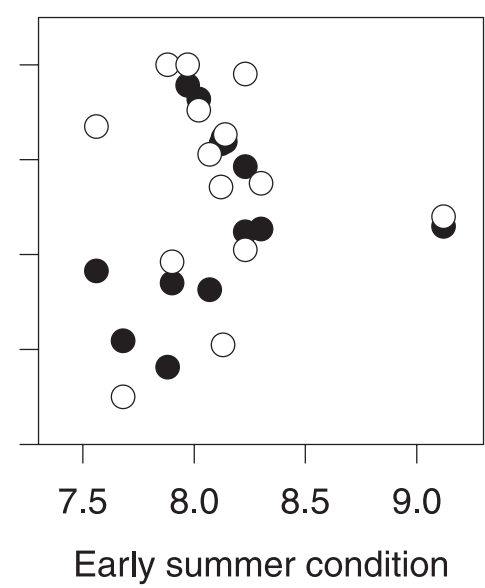

Spawning may be a source of mortality that we could not adequately assess. Arctic grayling are spring spawners and as such are called upon to invest resources in reproduction when body reserves are at a minimum. Adult Arctic grayling typically lose an average of $10 \%$ of their body weight (range $0 \%-20 \%$ ) over the winter prior to spawning (L.A. Deegan, unpublished data). It might be expected that spawning mortality would occur in fish in the poorest condition and would therefore be included in any relationship between condition and survival. Arctic grayling may instead follow the same strategy as Arctic char (Salvelinus alpinus), which do not spawn when they have spent the previous year in unproductive habitats (Dutil 1986). This strategy would not be reflected in any measure that we have available, nor do we know if Arctic grayling use this strategy.

Other reasons that we were unable to find a single or combination of parameters in a year that correlated well with survival may be that there are multiyear effects where the population is capable of withstanding one stressful year but a second or third stressful year would have a disproportionately large effect on survivorship. This type of multiyear conditional mortality cannot be adequately addressed using program MARK.

Another possibility is that survival rates were relatively unresponsive to environmental conditions. The Arctic is a harsh environment with a short growing season and strong nutrient limitation in both aquatic (O'Brien et al. 1992; Peterson et al. 1993) and terrestrial ecosystems (Shaver and Chapin 1995). Most organisms require multiple growing seasons to acquire sufficient biomass and resources to reproduce. In addition, there was considerable interannual variation in environmental conditions. Deegan et al. (1999) demonstrated that conditions favoring adult Arctic grayling growth do not favor growth of young-of-the-year. Within this framework of variability, there is a high likelihood that in any given year there will be poor survival of young-of-theyear or a year-class failure, which is reflected in the observed variability in recruitment into the adult population. Spreading reproduction over several years increases the probability that some offspring will survive to become adults. However, to accomplish this, adult survival rates must remain high and relatively unaffected by resource levels. Life history theory predicts that in long-lived species, resource availability will affect fecundity rather than adult survival (Stearns 1976), and this has been demonstrated in seabirds (Oro et al. 1999). Arctic grayling may be following the same strategy.

This study provides one of the few long-term survival estimates for an Arctic fish. Arctic regions are most likely to experience the greatest degree of warming under all global change scenarios (IPCC 2001). Arctic grayling in streams of Alaska's North Slope face additional challenges as this area 
becomes more accessible to resource extraction (gravel mining, oil drilling, and transport) and fishing pressure. Owing to the remoteness of the study site and the sampling design, these estimates of survival for the most part exclude anthropogenic effects on the population and as such provide a baseline against which anthropogenic effects may be evaluated.

This study should also sound a note of caution. Arctic grayling are a game fish and they can face substantial fishing pressure. Clark (1992) estimated instantaneous fishing mortality to be 0.45 for Chena River Arctic grayling. Fish stocks are often managed assuming density dependence where natural mortality is substituted for by fishing mortality. With little evidence for density dependence regulating this Arctic population or the subarctic Chena River population, fishing mortality may instead be added to natural mortality. Iteroparous populations with variable survival rates such as Arctic grayling face the greatest risks of local extinction (Jonsson and Ebenman 2001). Care must be taken to avoid depletion of grayling stocks through overfishing or other anthropogenic activities, especially in the Arctic where growth rates are low and recruitment is variable. Stocking efforts by the Alaska Department of Fish and Game have not been successful in replenishing Arctic grayling stocks that have been overfished (Clark 1996). In addition, natural recolonization of areas of local extinction will be slow because of the high site fidelity that Arctic grayling display to their summer feeding locations (Buzby and Deegan 2000). The geographic range of Arctic grayling has been decreasing because of overfishing and extirpation (Kaya 1991; Northcote 1995; Clark 1996). All evidence indicates that it is considerably more difficult to restore Arctic grayling populations than it is to maintain them.

\section{Acknowledgements}

This research was supported by National Science Foundation grants OPP-9911278 and DEB-9810222 in conjunction with the Long-term Ecological Research Program. The authors gratefully thank the numerous colleagues for their contribution, especially Carolyn Bauman, Chris Harvey, Heidi Golden, Robert Golder, and Stan Peterson. We thank Rob Gieck of University of Alaska-Fairbanks for his assistance with the Kuparuk River snowmelt data. We also thank the staff of the Toolik Lake Field Station for their logistical support.

\section{References}

Barker, R.J. 1999. Joint analysis of mark-recapture, resighting and ring-recovery data with age-dependence and marking effect. Bird Study, 46(Suppl.): 82-91.

Burnham, K.P., and Anderson, D.R. 1998. Model selection and inference: a practical information-theoretic approach. Springer-Verlag, New York.

Buzby, K., and Deegan, L. 1999. Retention of anchor and passive integrated transponder tags by Arctic grayling. N. Am. J. Fish. Manag. 19: 1147-1150.

Buzby, K.M, and Deegan, L.A. 2000. Inter-annual fidelity to summer feeding sites in Arctic grayling. Environ. Biol. Fishes, 59: 319-327.
Cargnelli, L.M., and Gross, M.R. 1997. Fish energetics: larger individuals emerge from winter in better condition. Trans. Am. Fish. Soc. 126: $153-156$.

Clark, R.A. 1992. Influence of stream flows and stock size on recruitment of Arctic grayling (Thymallus arcticus) in the Chena River, Alaska. Can. J. Fish. Aquat. Sci. 49: 1027-1034.

Clark, R.A. 1996. Stock status and rehabilitation of Chena River Arctic grayling during 1995. Alaska Dep. Fish Game Fish. Data Ser. No. 96-2.

Deegan, L.A., and Peterson, B.J. 1992. Whole-river fertilization stimulates fish production in an Arctic tundra river. Can. J. Fish. Aquat. Sci. 49: 1890-1901.

Deegan, L.A., Golden, H.E., Harvey, C.J., and Peterson, B.J. 1999. Influence of environmental variability on the growth of age-0 and adult Arctic grayling. Trans. Am. Fish. Soc. 128: 1163-1175.

De Leo, G.A., and Gatto, M. 1996. Trends in vital rates of the European eel: evidence for density dependence. Ecol. Appl. 6: 1281-1294.

Dutil, J.-D. 1986. Energetic constraints and spawning interval in the anadromous Arctic charr (Salvelinus alpinus). Copeia, 4: 945-955.

Frederiksen, M., and Bregnballe, T. 2000. Evidence for densitydependent survival in adult cormorants from a combined analysis of recoveries and resightings. J. Anim. Ecol. 69: 737-752.

Heppel, S.S., Crowder, L.B., and Caswell, H. 2000. Life histories and elasticity patterns: perturbation analysis for species with minimal demographic data. Ecology, 81: 654-665.

Hershey, A.E., Bowden, W.B., Deegan, L.A., Hobbie, J.E., Peterson, B.J., Kipphut, G.W., Kling, G.W., Lock, M.A., Merritt, R.W., Miller, M.C., Vestal, J.R., and Schuldt, J.A. 1997. The Kuparuk River: a long-term study of biological and chemical processes in an Arctic river. In Freshwaters of Alaska. Edited by A.M. Milner and M.W. Oswood. Springer, New York. pp. 107-129.

Hughes, N.F. 1992. Selection of positions by drift-feeding salmonids in dominance heirarchies: model and test for Arctic grayling (Thymallus arcticus) in subarctic mountain streams, interior Alaska. Can. J. Fish. Aquat. Sci. 49: 1999-2008.

Intergovernmental Panel on Climate Change (IPCC). 2001. Climate change 2001: the scientific basis. Edited by J.T. Houghton, Y. Ding, D.J. Griggs, M. Noguer, P.J. van der Linden, and D. Xiaosu. Cambridge University Press, Cambridge, UK.

Jonsson, A., and Ebenman, B. 2001. Are certain life histories particularly prone to local extinction. J. Theor. Biol. 209: 455-463.

Kaya, C.M. 1991. Rheotactic differentiation between fluvial and lacustrine populations of Arctic grayling (Thymallus arcticus), and implications for the only remaining indigenous population of fluvial "Montana Grayling". Can. J. Fish. Aquat. Sci. 48: 53-59.

Lebreton J.D., Burnham, K.P., Clobert, J., and Anderson, D.R. 1992. Modeling survival and testing biological hypotheses using marked animals: a unified approach with case studies. Ecol. Monogr. 62: 67-118.

Northcote, T.G. 1995. Comparative biology and management of Arctic and European grayling (Salmonidae, Thymallus). Rev. Fish Biol. Fish. 5: 141-194.

O'Brien, W.J., Hershey, A.E., Hobbie, J.E., Hullar, M.A., Kipphut, G.W., Miller, M.C., Moller, B., and Vestal, J.R. 1992. Control mechanisms of arctic lake ecosystems: a limnocorral experiment. Hydrobiologia, 240: 143-188.

Oro, D., Pradel, R., and Lebreton, J.-D. 1999. Food availability and nest predation influence life history traits in Audouin's, Larus audouinii. Oecologia, 118: 438-445.

Peterson, B.J., Deegan, L., Helfrich, J., Hobbie, J.E., Hullar, M., Moller, B., Ford, T.E., Hershey, A., Hiltner, A., Kipphut, G., Lock, M.A., Fiebig, D.M., McKinley, V., Miller, M.C., Vestal, 
J.R., Ventullo, R., and Volk, G. 1993. Biological responses of a tundra river to fertilization. Ecology, 74: 653-672.

Sæther, B.-E., and Bakke, O. 2000. Avian life history variation and contribution of demographic traits to the population growth rate. Ecology, 81: 642-653.

Shaver, G.R., and Chapin, F.S., III. 1995. Long-term responses to factorial, NPK fertilizer treatment by Alaskan wet and moist tundra sedge species. Ecography, 18: 259-275.

Slavik, K., Peterson, B.J., Deegan, L.A., Bowden, W.B., Hershey, A.E., and Hobbie, J.E. 2004. Long-term responses of the Kuparuk River to fertilization. Ecology, 85: 939-954.

Sogard, S.M., and Olla, B.L. 2000. Endurance of simulated winter conditions by age- 0 walleye pollock: effects of body size, water temperature and energy stores. J. Fish Biol. 56: 1-21.
Stearns, S.C. 1976. Life history tactics: a review of the ideas. Q. Rev. Biol. 51: 3-47.

Stearns, S.C. 1992. The evolution of life histories. Oxford University Press, Oxford, UK.

White, G.C., and Burnham, K.P. 1999. Program MARK: survival estimation from populations of marked animals. Bird Study, 46(Suppl.): 120-139.

Wildy, E.L., Chivers, D.P., Kiesecker, J.M., and Blaustein, A.R. 2001. The effects of food level and conspecific density on biting and cannibalism in larval long-toed salamanders, Ambystoma macrodactylum. Oecologia, 128: 202-209.

Wootton, R.J. 1998. Ecology of teleost fishes. 2nd ed. Kluwer Academic Publishers, Dordrecht, the Netherlands. 